\title{
Antiglaucoma drugs for achieving monovision after laser in situ keratomileusis
}

\author{
Kazutaka Kamiya \\ Kimiya Shimizu \\ Department of Ophthalmology, \\ University of Kitasato School \\ of Medicine, Japan
}

\begin{abstract}
We report on a patient in whom the use of antiglaucoma drugs has been beneficial for the attainment of monovision after laser in situ keratomileusis (LASIK). A 57-year-old woman undergoing LASIK complained of blurred vision in the right eye. After a successful trial of monovision with contact lenses, antiglaucoma drugs ( $2.5 \%$ nipradilol) were administered topically to the right eye twice a day to establish monovision. In the right eye, the manifest refraction was changed from $-4.0,-1.0 \times 80$, with an uncorrected visual acuity (UCVA) of 0.3 for near vision before treatment, to $-2.5,-1.0 \times 80$, with an UCVA of 0.9 for near vision after treatment, while, in the left eye, it was $0,-1.0 \times 100$, with an UCVA of 0.9 for far vision. Binocular UCVA was improved from 0.3 for near and 0.9 for distance vision before treatment, to 0.9 for near and 1.0 for distance vision after treatment. No complications were observed and the manifest refraction remained stable during the 6-month follow-up period. The use of antiglaucoma drugs may be helpful for the achievement of monovision by reduction of myopic regression after LASIK.
\end{abstract}

Keywords: antiglaucoma drugs, regression, monovision, LASIK

\section{Introduction}

Excimer laser surgery has for years been a routine procedure for the correction of myopia, hyperopia, and astigmatism. However, myopic regression of the initial surgical effect can affect the predictability, efficiency, and long-term stability of keratorefractive surgery, leading to deterioration in visual performance. Actually, it is well known that some regression may occur not only after photorefractive keratectomy (PRK) but also after laser in situ keratomileusis (LASIK), especially when the amount of myopic correction is large, ${ }^{1-5}$ but the mechanism for myopic regression still remains to be elucidated. We have already shown that antiglaucoma drugs are effective for the reduction of refractive regression after LASIK. ${ }^{6}$

Monovision has been reported to be an effective method for the management of presbyopia where the one eye is corrected for distance vision and the other for near. It has also been used for presbyopic patients after LASIK. ${ }^{7,8}$ Nonetheless, to our knowledge, there have been no previous case reports on the management of monovision after LASIK with the use of antiglaucoma drugs in eyes with presbyopia. We present herein a case in which the use of antiglaucoma eye drops was helpful for the establishment of monovision by reducing regression after LASIK.

\section{Case report}

A 57-year-old woman, who had undergone bilateral LASIK to correct myopia of -11.75 diopters (D) in both eyes eight years earlier, was referred to our hospital with a complaint of blurred near vision in the right eye. The manifest refraction was $-4.0,-1.0 \times 80$, with an uncorrected visual acuity (UCVA) of 0.3 for near and 0.07 for distance vision, and a best spectacle-corrected visual acuity (BSCVA) of 1.2 in the right eye, and was $0,-1.0 \times 100$, with an UCVA of 0.9 and a BSCVA 
of 1.2 in the left eye. Binocular UCVA was 0.3 for near and 0.9 for distance vision. The keratometry was 40.8/41.3 $\mathrm{D} \times 170$; the central corneal thickness (CCT), $433 \mu \mathrm{m}$; and the intraocular pressure (IOP), $11 \mathrm{mmHg}$ in the right eye (Table 1). Scanning-slit corneal topography (Orbscan; Bausch and Lomb, Rochester, NY, USA) showed a marked central thinning of the cornea (Figure 1). Other ophthalmic examination findings were unremarkable. The left eye was dominant, and the right eye, nondominant according to the hole-in-card test. We confirmed a successful trial of monovision with contact lenses. After informed consent was obtained from the patient, topical antiglaucoma drugs (2.5\% nipradilol; Kowa, Tokyo, Japan) were continuously administered to the right eye twice a day to establish monovision. At 1 month after application, the mean refraction was $-2.5,-1.00 \times 80$, with an UCVA of 0.9 for near and 0.15 for distance vision, and a BSCVA of 1.2. Binocular UCVA was 0.9 for near and 1.0 for distance vision. The keratometry was $39.8 / 40.3 \mathrm{D} \times 175$ in the right eye. The CCT was $434 \mu \mathrm{m}$. The IOP was $9 \mathrm{mmHg}$ (Table 1). No vision-threatening complications occurred, and the manifest refraction remained unchanged, throughout the six-month observation period.

\section{Discussion}

In this case, the near UCVA was 0.3 and the manifest refraction was $-4.0,-1.0 \times 80$ in the right eye, which was insufficient for achieving monovision with good near vision, and the patient complained of anisometropic asthenopia. Moreover, enhancement surgery should be avoidable because of its side effect of biomechanical weakening of the cornea as evidenced by a marked central thinning (CCT, $433 \mu \mathrm{m}$, thinnest CT, $408 \mu \mathrm{m}$ ). We have already demonstrated that antiglaucoma drugs are effective for the reduction of myopic regression, especially that of spherical errors, which presumably results from the backward movement of the cornea and the flattening of its curvature after LASIK without affecting CCT. ${ }^{6}$ On the assumption that monovision is likely to be established if the small amount of regression in the right eye can be reduced, we performed an additional antiglaucoma treatment to that eye only in this case. Although excessive monovision may be unacceptable to the patient, it was clinically acceptable to this patient aged 57 years with an anisometropia of $2.5 \mathrm{D}$. At present, we have no clear explanation of why the refraction was improved by as much as $1.5 \mathrm{D}$ in this case. We have already demonstrated that corneal biomechanical parameters are decreased not only in eyes with thinner $\mathrm{CCT},{ }^{9}$ but also in the eyes of older patients. ${ }^{9,10}$ We speculate that the corneal biomechanical changes due to a thin cornea and increasing patient age may contribute to the unexpected refractive outcomes in this case, because these changes tend to induce greater flattening of the cornea, leading to greater refractive improvement.

Nipradilol, a nonselective alpha-1 beta adrenergic antagonist with nitroglycerine-like activity, is widely used in Japan as a safe and useful long-term antihypertensive drug that lowers IOP by decreasing the aqueous flow rate and by increasing uveoscleral outflow, ${ }^{11,12}$ although it is contraindicated for the patients with cardiovascular disease or with asthma. Therefore, we selected it as the therapeutic option for the regressive eye.

There are concerns about the possible long-lasting effects of the treatment. If the refractive effects depend simply on the degree of IOP reduction, patients could be compelled to use the antiglaucoma drugs continuously. We are planning further studies to confirm whether or not this refractive effect is maintained after long-term cessation of the medication.

Table I Patient demographics before and after nipradilol treatment

\begin{tabular}{|c|c|c|}
\hline & Pre-treatment & Post-treatment (I mo) \\
\hline & \multicolumn{2}{|l|}{ Monocular (right eye, nondominant) } \\
\hline Mean refraction & $-4.0,-1.0 \times 80$ & $-2.5,-1.0 \times 80$ \\
\hline Near UCVA & 0.3 & 0.9 \\
\hline Far UCVA & 0.07 & 0.15 \\
\hline Keratometry (D) & $40.8 / 41.3 \mathrm{D} \times 170$ & $39.8 / 40.3 \mathrm{D} \times 175$ \\
\hline CCT $(\mu \mathrm{m})$ & 433 & 434 \\
\hline \multirow[t]{2}{*}{ IOP $(\mathrm{mmHg})$} & II & 9 \\
\hline & \multicolumn{2}{|l|}{ Binocular } \\
\hline Near UCVA & 0.3 & 0.9 \\
\hline Far UCVA & 0.9 & 1.0 \\
\hline
\end{tabular}

Abbreviations: mo, month; UCVA, uncorrected visual acuity; CCT, central corneal thickness; IOP, intraocular pressure. 


\section{OORBSCAN}
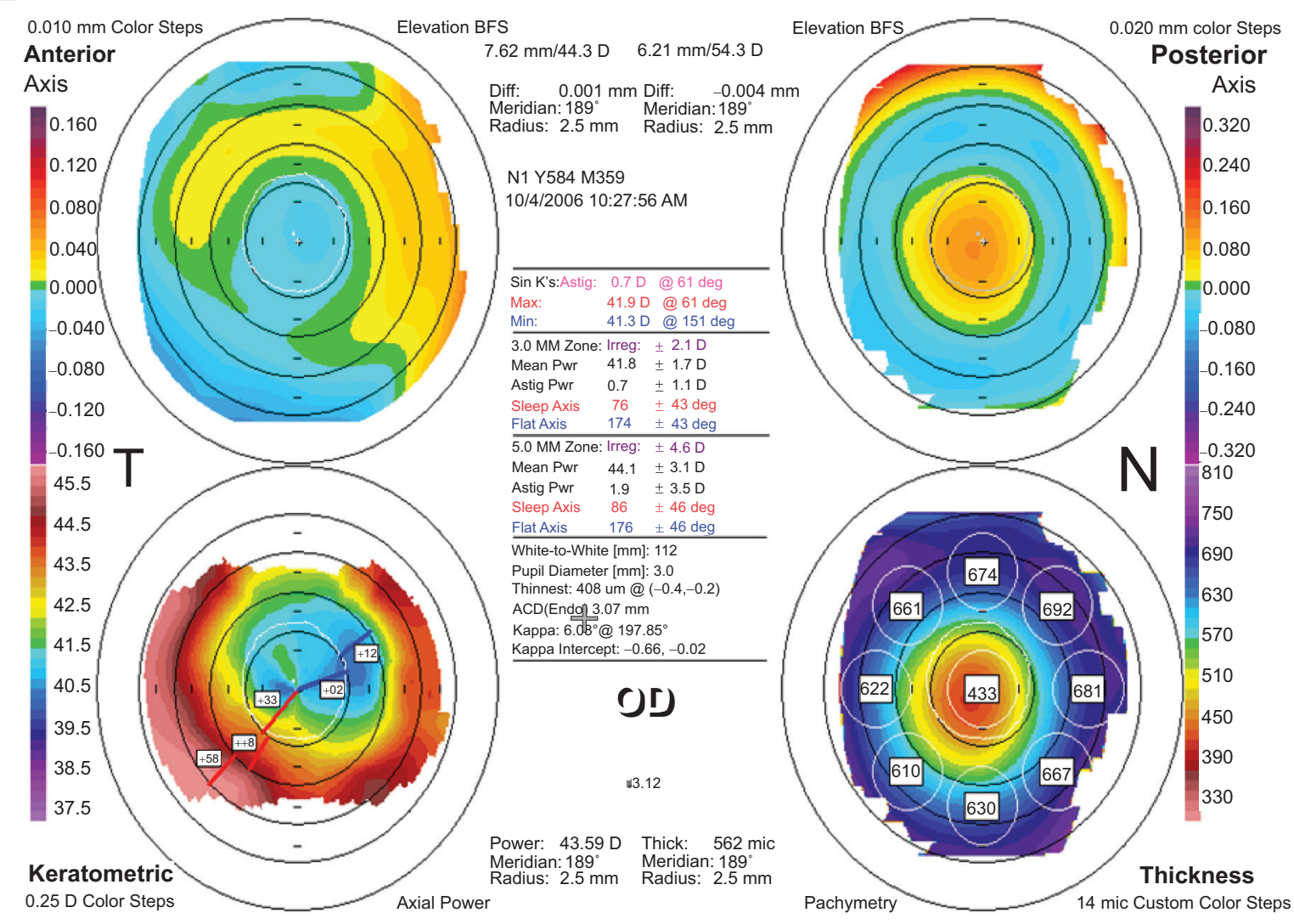

Figure I The scanning-slit corneal topography displays marked central thinning of the cornea.

Our case report suggests that the use of antiglaucoma drugs may contribute to the reduction of refractive regression, resulting in the achievement of monovision after LASIK in eyes with presbyopia. Although we accept that it does not frequently occur that antiglaucoma drugs are effective for the attainment of monovision after LASIK in the manner shown in this case, we believe that this treatment is clinically applicable especially to biomechanically weakened eyes such as those with thinned corneas after LASIK, because it appeared to be less invasive and to cause fewer side effects (eg, keratectasia) than enhancement surgery.

\section{Disclosure}

The authors report no conflicts of interest in this work.

\section{References}

1. Knorz MC, Liermann A, Seiberth V, et al. Laser in situ keratomileusis to correct myopia of -6.00 to -29.00 diopters. J Refract Surg. 1996; 12:575-584.

2. Perez-Santonja JJ, Bellot J, Claramonte P, et al. Laser in situ keratomileusis to correct high myopia. J Cataract Refract Surg. 1997; 23:372-385.
3. Lohmann CP, Guell JL. Regression after LASIK for the treatment of myopia: the role of the corneal epithelium. Semin Ophthalmol. 1998; 13:79-82.

4. Chayet AS, Assil KK, Montes M, et al. Regression and its mechanisms after laser in situ keratomileusis in moderate and high myopia. Ophthalmology. 1998;105:1194-1199.

5. Hersh PS, Brint SF, Maloney RK, et al. Photorefractive keratectomy versus laser in situ keratomileusis for moderate to high myopia. A randomized prospective study. Ophthalmology. 1998;105:1512-1522.

6. Kamiya K, Aizawa D, Igarashi A, Komatsu M, Shimizu K. Effects of antiglaucoma drugs on refractive outcomes in eyes with myopic regression after laser in situ keratomileusis. Am J Ophthalmol. 2008; 145:233-238.

7. Goldberg DB. Laser in situ keratomileusis monovision. $J$ Cataract Refract Surg. 2001;27:1449-1455.

8. Cheng AC, Lam DS. Monovision LASIK for pre-presbyopic and presbyopic patients. J Refract Surg. 2005;21:411-412.

9. Kamiya K, Hagishima M, Fujimura F, Shimizu K. Factors affecting corneal hysteresis in normal eyes. Graefes Arch Clin Exp Ophthalmol. 2008;246:1491-1494.

10. Kamiya K, Shimizu K, Ohmoto F. Effect of aging on corneal biomechanical properties using the ocular response analyzer. $J$ Refract Surg. 2009:1 In press.

11. Haneda T, Ogawa Y, Akaishi T, et al. Efficacy of long-term treatment with nipradilol, a nitroester-containing beta-blocker, in patients with mild-to-moderate essential hypertension. Clin Ther. 1995;17:667-679.

12. Kanno M, Araie M, Koibuchi H, Masuda K. Effects of topical nipradilol, a beta blocking agent with alpha blocking and nitroglycerin-like activities, on intraocular pressure and aqueous dynamics in humans. Br J Ophthalmol. 2000;84:293-299. 
